\title{
Nutritional concerns, health and survival in old age
}

\author{
C. P. G. M. de Groot • W. A. van Staveren
}

Received: 23 February 2010/ Accepted: 7 May 2010/Published online: 21 May 2010

(C) The Author(s) 2010. This article is published with open access at Springerlink.com

\begin{abstract}
The ageing process is - apart from chance or good luck - not only influenced by factors intrinsic to the individual, but also by extrinsic factors that include environmental and lifestyle variables. This paper deals with the epidemiological evidence for the role of dietary patterns and key nutritional concerns in relation to survival and ageing related disorders that present themselves in later life. Dietary patterns, such as the Mediterranean diet, characterized by mainly plant foods including protective factors e.g. vegetables, nuts and monounsaturated fatty acids and excluding harmful factors e.g. trans-fatty acids and foods with a high glycemic factor, appear to be relevant even in old age. Specific nutritional concerns focus on general undernutrition, vitamin $\mathrm{D}$ and vitamin $B_{12}$. Prevalence of nutritional inadequacies, diagnostic criteria, causes and health consequences are described. The paper ends with recommendations for guidance on healthy diets for elderly people. An important challenge should be research to further expand the knowledge base, acknowledging the complexity of the ageing process and integrating different dimensions of research into human healthy ageing in properly designed studies. In the mean time reversing poor adherence to existing guidelines for a
\end{abstract}

C. P. G. M. de Groot $(\bowtie)$. W. A. van Staveren Human Nutrition, Wageningen University, Bomenweg 2, 6703 HD Wageningen, The Netherlands

e-mail: Lisette.deGroot@wur.nl healthy diet remains a first challenge in public health nutritional practices.

Keywords Nutrition · Aged · Health · Survival

\section{Ageing and nutrition}

Many industrialized countries now have ageing populations, mostly as a consequence of declining fertility and mortality in later life. Globally the proportion of older persons, defined as aged 60 years or over, has risen from $8 \%$ in 1950 to $11 \%$ in 2007, and is expected to reach $22 \%$ in 2050 (United Nations, 2007). Even though most people reach old age in reasonable health, they are facing potential consequences of the ageing process, defined as the gradual, lifelong accumulation of molecular and cellular damage, eventually resulting in progressive loss of function, frailty and disease (Kirkwood 2008). Common features, such as the development of a chronic, low grade, inflammatory status-or inflammaging-are implicated in several age-associated disorders and, they may reflect overlapping biological mechanisms (Franceschi 2007). How the ageing process plays out is complicated as-apart from chance or good luckit is not only influenced by factors intrinsic to the individual but also by extrinsic factors that include environmental and lifestyle variables, such as exercise and nutrition (Kirkwood 2008). As yet, there is 
substantial mechanistic evidence that it is possible to impact on the interplay between intrinsic factors and nutrition. Moreover, in the past decades many epidemiological studies have found significant associations between diet quality and the prevention of chronic disease and mortality, whereby nutrition intervention studies start to show benefits for dietary patterns and specific nutrients. The present paper aims to address the epidemiological evidence for the role of dietary patterns and key nutritional concerns in relation to survival and ageing related disorders that present themselves later in life.

\section{Dietary patterns and survival}

The dietary intake of foods and nutrients are related, and, as people do not eat single nutrients or foods, evaluating dietary patterns has attracted considerable interest in nutritional epidemiology. Assessing dietary quality by dietary patterns has the advantage of capturing the high inter-correlation of nutrients within a diet, as well as integrating complex interactive effects of many dietary exposures. This recently followed from a systematic review of 601 studies across all ages, supporting a causal link between dietary factors and dietary patterns with coronary heart disease (Mente et al. 2009). By combined analysis of strictly defined prospective studies, strong evidence was found of a causal relationship for protective factors, comprising intake of vegetables (RR 0.83), nuts (RR 0.67) and monounsaturated fatty acids (RR 0.81) and Mediterranean (RR 0.66), prudent and high-quality dietary patterns (RR 0.63), and for harmful factors, such as intake of trans-fatty acids (RR 1.31) and foods with a high glycemic index or load (RR 1.33) and western dietary pattern (RR 1.33). In randomized controlled trials only a Mediterranean dietary pattern (RR 0.32) was related to coronary heart disease. Adherence to such a Mediterranean diet appears to be relevant even in old age. Reductions of $9 \%$ in overall mortality, mortality from cardiovascular diseases (9\%), mortality from cancer $(6 \%)$ and incidence of Alzheimer's disease $(13 \%)$ followed from a meta-analysis of eight cohort studies (Sofi et al. 2008). Additional evidence from two prospective studies suggests that adherence to the Mediterranean diet may not only affect the risk for Alzheimer's disease, but also slows the disease course, with a trend towards reduced risks for developing Mild Cognitive Impairment, for conversion of Mild Cognitive Impairment to Alzheimer's disease and for Alzheimer's disease (Féart et al. 2010).

In the European Prospective Investigation into Cancer and Nutrition, the EPIC-Elderly Study it has been questioned how each individual component of the Mediterranean Diet contributes to the observed beneficial effects. Several of these components appeared to reduce mortality risk either with above median intakes-vegetables, fruits, cereals, fish and/ or the ratio of unsaturated to saturated lipids—or with below median intakes for saturated fat. Generally, a plant-based diet, which correlated well with a Mediterranean diet $(r=0.62)$ and which was merely relying on the intake of plant foods, the avoidance of margarine, non-alcoholic beverages and potatoes appeared to be associated with lower all-cause mortality in elderly Europeans from the EPIC-study (Bamia et al. 2007). Explanatory routes include the pleiothropic effects, including those against inflammation, that specific food components such as polyphenols (Williamson and Manach, 2005) and omega-3 fatty acids (Riediger et al. 2009) may have. These however, require further carefully designed efficacy studies to underpin their wider health benefits (Cole and Frautschy 2010).

From a public health perspective it is noteworthy that the adherence to Mediterranean types of diet is lowest in the younger cohorts and tends to increase with aging. For example, Trichopoulou et al. 2005 reported that the prevalence of the highest Mediterranean Diet Score progressively increased from $25.2 \%$ in the $60-64$ age group to $41.4 \%$ in people $\geq 75$ years old according to data from the EPICelderly cohort study. These trends are likely explained by cohort effects and secular trends, suggesting that adherence to the Mediterranean diet would dramatically decrease in the near future.

Most challenging are observed interactions between gene polymorphisms and metabolic responses to Mediterranean type of diets, which require further investigation prior to their translation (Lairon et al. 2009). Much more established is the evidence for the effect of adherence to a healthful, Mediterranean type of diet along with other healthful lifestyle practices, including nonsmoking, moderate alcohol consumption and physical activity. Taken 
together, the combinations of lifestyle practices appeared to be associated with a mortality rate of about one-third that of those with none or only of these healthful lifestyle behaviors (Knoops et al. 2004) and with an estimated increase in life-expectancy of $2 \pm 0.3$ years.

\section{Specific nutritional concerns in old age}

In general the nutritional requirements of older adults are the same as for the rest of the adult population though for some nutrients, including for example vitamin D and vitamin B12, an adequate supply is hard to achieve, even with an apparently adequate food intake.

In most European countries, the percentage of the population with vitamin $\mathrm{D}$ insufficiency is high among the aged, but prevalences vastly depend on the required serum $25(\mathrm{OH}) \mathrm{D}$ level (Mithal et al. 2009). The European Survey on Nutrition and the Elderly (SENECA) on independently living older persons showed that $40 \%$ had serum 25 -hydroxyvitamin D (25OH)D levels below $30 \mathrm{nmol} / 1$ (de Groot et al. 2004). The latter standard is much below the currently proposed level of at least $50 \mathrm{nmol} / \mathrm{l}$ (Mosekilde 2008). Approximately one-third of the vitamin $\mathrm{D}$ requirements can be obtained from the diet. The rest is synthesized in the skin under the influence of sunlight. As a result of limited sunlight exposure and a fourfold reduced capacity of the skin to produce vitamin $\mathrm{D}$, deficiencies may occur even in apparently healthy older people (Lips et al. 2001). In most countries, dietary intakes of mostly vitamin D are far lower than recommended levels (Mosekilde 2008). As a consequence, options for optimizing vitamin D status, depending largely on medical, social, cultural, legal and financial aspects-e.g. vitamin D supplements or vitamin D enriched food products-have been implemented or are still considered across Europe (Weggemans et al. 2009).

As for vitamin D, vitamin B12 deficiency is highly prevalent in the elderly. Among elderly participants of the SENECA study in Europe, some 25\% had plasma cobalamin levels $<260 \mathrm{pmol} / \mathrm{l}$ and plasma methylmalonic acid (MMA) levels $>0.32 \mu \mathrm{mol} / 1$ (de Groot et al. 2004). Both vitamin D and vitamin B12 are predominantly derived from animal sources. However, deficiencies can occur when in the case of vitamin B12 malabsorption is present. Atrophic gastritis reduces the absorption of several nutrients, which leads, especially for vitamin B12 to a deficiency state, which only partly could be explained by dietary intake or atrophic gastritis. As yet there is no evidence that vitamin B12 is handled differently in old age once the vitamin is absorbed. Therefore, other factors responsible for the cobalamin deficiency need to be sought.

Though general undernutrition is not common in the community dwelling elderly, elderly people are at risk for developing poor nutritional status. Reasons are multifaceted and include the physiological, psychological and social changes associated with aging which affect food intake and body weight, possibly exacerbated by the presence of illness. Inadequate nutritional intake is the predominant cause of under nutrition in old age. When intakes decline to levels below requirements, foods which are nutrient-dense become particularly important (Morley and van Staveren 2009).

\section{Consequences of nutritional inadequacies}

Much remains to be learned about how nutrition interacts with intrinsic and extrinsic factors in order to extend healthy life expectancy, independence and well-being in old age. In the mean time observational studies continue to provide clues to healthy ageing, whilst supporting evidence from well-designed controlled trials needs to be expanded.

Vitamin $D$ is with calcium known for its critical importance for bone health. Both seem crucial targets for preventive and treatment measures of osteoporosis. On whether or not to combine the two nutrients, not only randomised trials examining the effect of vitamin D supplementation-with or without calcium-on the incidence of fractures/falls have produced conflicting results, but also recent metaanalyses do so, even within 1 year.

- “A higher received dose of supplemental vitamin D (482-770 UI/d) should reduce fractures by at least $18 \%$; the addition of calcium to adequate intakes of vitamin $\mathrm{D}$ does not seem to enhance the effect of vitamin D" (Bischoff-Ferrari et al. 2009)

- "Vitamin D alone appears unlikely to be effective in preventing hip fracture. Vitamin D with calcium reduces hip fractures (RR 0.84, 95\% CI 0.73-0.96)" (Avenell et al. 2009). 
The latest analysis of individual patients' data from seven large fracture trials however indicates that vitamin $\mathrm{D}$ with calcium reduces the overall risk of fracture (RR 0.92 (0.86-0.99)), and probably hip (RR $0.84(0.70-1.01))$ and clinical vertebral fracture, irrespective of sex and fracture history. It concludes that additional studies of vitamin D are needed, given daily without calcium (Dipart 2010).

Recent research has shown that vitamin D generates more biological responses than previously thought. As illustrated by the tissue distribution of the VDR the biological effects of vitamin D are widening, from mediating only calcium homeostasis to functioning in other physiologic areas including the immune system, insulin secretion by the pancreatic $\beta$ cell, heart functioning and blood pressure regulation, and brain function (Norman 2008). Thus deficiency may affect the broader spectrum of functional outcomes, involving brain, muscle, vascular and heart health.

Vitamin B12 deficiency has widely been known as 'pernicious anemia', arising from an uncommon lack of intrinsic factor due to severe gastric atrophy. In old age the main cause of deficiency is food-cobalamin absorption, characterized by the inability to release vitamin B12 from food or its binding proteins. Cobalamin deficiency manifests itself in a variety of ways, hematological, gastrointestinal and neurological. There is accumulating evidence that the combination of low vitamin B12 and high folate (further to the addition of folic acid to the food supply) may accelerate the progression of neurological damage from the vitamin B12 deficiency, increasing the odds of cognitive impaired almost 5-fold (Selhub et al. 2009). If treated relatively soon, the neurological complications are-as the hematologic symptomsreversible. The small number of efficacy studies which have been done so far, provide however no consistent evidence either way, that vitamin B12 and/ or folic acid have a beneficial effect on cognitive function of unselected healthy or cognitively impaired older people. Only one long-term study appeared to improve the cognitive function-or rather slow down cognitive decline by $2-5$ yearsof healthy older people with high homocysteine levels (Malouf and Grimley Evans 2008).

In the past decade it has been shown that vitamin $\mathrm{B}$ is also involved in bone health. Its deficiency may lead to decreased bone mass by increased osteoclast formation due to increased MMA and Hcy levels (Vaes et al. 2010). Two prospective studies demonstrate that increased homocysteine levels double the risk of fractures (van Meurs et al. 2004), which finds support in one homocysteine lowering trial in post-stroke patients (Sato et al. 2005).This single study needs further confirmation from additional trials.

Undernutrition is one of the features of malnutrition, which has been defined as a state of nutrition in which a deficiency or excess (or imbalance) of energy, protein, and other nutrients causes measurable adverse effects on tissue/body form (body shape, size and composition) and function, and clinical outcome (Lochs et al. 2006), It may have important effects on homeostatic reserve and resilience, functional losses and recovery. Its treatment should focus on identifying and treating modifiable causes of weight loss. The effects of single nutritional interventions on functional performance is an issue under discussion. A review on protein and energy supplementation in malnourished elderly reported evidence for weight gain, but found no evidence for positive effects on functional performance (Milne et al. 2009). Yet, 14 out of 20 exercise intervention studies jointly suggest that older adults with different levels of abilities can improve their functional performance by regular exercise training (Chin et al. 2008), whereby high-quality trials are needed in which different training protocols with or without nutritional support are still warranted.

\section{Recommendations and guidelines}

With basically similar nutritional requirements as the adult population at large, in old age both the quality and the quantity of the diet are important to ensure that requirements for both macronutrient and micronutrient intakes are met. However, as older people age, they may need fewer calories because they are not as physically active as when they were younger and their metabolic rate slows down. As a result nutrients and food components need to be obtained with less energy intake and nutrient and food density of the diet needs to increase (Drewnowski 2005). Thus guidance on healthy diets for elderly people needs to allow for: 
- Population guidelines on food intake, in view of the maintenance of a healthy body weight/body composition (energy, protein), an adequate supply of micronutrients (e.g. antioxidants), and specific components (e.g. n-3 fatty acids, low sodium, balanced supply of B-vitamins)

- A growing need for nutrient-dense diets once energy requirement goes down with progressing age

- Specific nutrients of concern, the supply of which is hindered by poor endogenous synthesis and/or hindered absorption.

Generic guidance on a healthy diet for older people is provided by national and international bodies (WHO: Keep fit for life; UK: Food Standard Agency; USDA: Dietary Guidelines for Americans). Hereby the focus on nutrition and ageing has expanded from the prevention of undernutrition to the critical role of diet in healthy ageing, with primarily investments in the field of age-related disorders. A major challenge for the future of nutrition and ageing research is to further expand the knowledge base, acknowledging the complexity of the ageing process (including its inflammatory features) and integrating different dimensions of research into human healthy ageing in properly designed studies. In the mean time reversing poor adherence to existing guidelines for a healthy dietalong with those for physical activity and other healthful lifestyle routines-remains a first challenge in public health nutritional practices.

Open Access This article is distributed under the terms of the Creative Commons Attribution Noncommercial License which permits any noncommercial use, distribution, and reproduction in any medium, provided the original author(s) and source are credited.

\section{References}

Avenell A, Gillespie WJ, Gillespie LD, O'Connell D (2009) Vitamin D and vitamin D analogues for preventing fractures associated with involutional and post-menopausal osteoporosis. Cochrane Database Syst Rev 15(2): CD000227

Bamia C, Trichopoulos D, Ferrari P, Overvad K, Bjerregaard L, Tjønneland A, Halkjaer J, Clavel-Chapelon F, Kesse E, Boutron-Ruault MC, Boffetta P, Nagel G, Linseisen J, Boeing H, Hoffmann K, Kasapa C, Orfanou A, Travezea C, Slimani N, Norat T, Palli D, Pala V, Panico S, Tumino
R, Sacerdote C, Bueno-de-Mesquita HB, Waijers PM, Peeters PH, van der Schouw YT, Berenguer A, MartinezGarcia C, Navarro C, Barricarte A, Dorronsoro M, Berglund G, Wirfält E, Johansson I, Johansson G, Bingham S, Khaw KT, Spencer EA, Key T, Riboli E, Trichopoulou A (2007) Dietary patterns and survival of older Europeans: the EPIC-Elderly Study (European Prospective Investigation into Cancer and Nutrition). Public Health Nutr 10(6):590-598

Bischoff-Ferrari HA, Willett WC, Wong JB, Stuck AE, Staehelin HB, Orav EJ, Thoma A, Kiel DP, Henschkowski J (2009) Prevention of nonvertebral fractures with oral vitamin D and dose dependency: a meta-analysis of randomized controlled trials. Arch Intern Med 169(6):551561

Chin A, Paw MJ, van Uffelen JG, Riphagen I, van Mechelen W (2008) The functional effects of physical exercise training in frail older people : a systematic review. Sports Med 38(9):781-793

Cole GM, Frautschy SA (2010) DHA may prevent age-related dementia. J Nutr 140:869-874

de Groot LC, Verheijden MW, de Henauw S, Schroll M, van Staveren WA, SENECA Investigators (2004) Lifestyle, nutritional status, health, and mortality in elderly people across Europe: a review of the longitudinal results of the SENECA study. J Gerontol A Biol Sci Med Sci 59(12):1277-1284

DIPART (Vitamin D Individual Patient Analysis of Randomized Trials) Group (2010). Patient level pooled analysis of 68500 patients from seven major vitamin D fracture trials in US and Europe. BMJ 340:b5463. doi: 10.1136/bmj. b5463

Drewnowski A (2005) Concept of a nutritious food: toward a nutrient density score. Am J Clin Nutr 82(4):721-732

Féart C, Samieri C, Barberger-Gateau P (2010) Mediterranean diet and cognitive function in older adults. Curr Opin Clin Nutr Metab Care 13(1):14-18

Franceschi C (2007) Inflammaging as a major characteristic of old people: can it be prevented or cured? Nutr Rev 65:S173-S176

Kirkwood TB (2008) A systematic look at an old problem. Nature 451:644-647

Knoops KT, de Groot LC, Kromhout D, Perrin AE, MoreirasVarela O, Menotti A, van Staveren WA (2004) Mediterranean diet, lifestyle factors, and 10-year mortality in elderly European men and women: the HALE project. JAMA 292(12):1433-1439

Lairon D, Defoort C, Martin JC, Amiot-Carlin MJ, Gastaldi M, Planells R (2009) Nutrigenetics: links between genetic background and response to Mediterranean-type diets. Public Health Nutr 12(9A):1601-1606

Lips P (2001) Vitamin D deficiency and secondary hyperparathyroidism in the elderly:consequences for done loss and fractures and therapeutic implications. Endocr Rev 22(4):477-501

Lochs H, Allison SP, Meier R, Pirlich M, Kondrup K, Scheider $S$ et al (2006) Introductory to the ESPEN guidelines on Enteral Nutrition: Terminology, Definitions and General topics. Clin Nutr 25:180-186

Malouf R, Grimley Evans J (2008) Folic acid with or without vitamin B12 for the prevention and treatment of healthy 
elderly and demented people. Cochrane Database Syst Rev (4):CD004514

Mente A, de Koning L, Shannon HS, Anand SS (2009) A systematic review of the evidence supporting a causal link between dietary factors and coronary heart disease. Arch Intern Med 169(7):659-669

Milne AC, Potter J, Vivanti A, Avenell A (2009) Protein and energy supplementation in elderly people at risk from malnutrition. Cochrane Database Syst Rev (2):CD003288

Mithal A, Wahl DA, Bonjour JP, Burckhardt P, DawsonHughes B, Eisman JA, El-Hajj Fuleihan G, Josse RG, Lips $\mathrm{P}$, Morales-Torres J, Committee IOF, IOF Committee of Scientific Advisors (CSA) Nutrition Working Group (2009) Global vitamin D status and determinants of hypovitaminosis D. Osteoporos Int 20(11):1807-1820

Morley JE, van Staveren WA (2009) Undernutrition: diagnosis, causes, consequences and treatment. In: Raats $\mathrm{M}$, de Groot L, van Staveren W (eds) Foof for the ageing population, 1st ed edn. Woodhead Publishing Limited, Cambridge, pp 153-166

Mosekilde L (2008) Vitamin D requirement and setting recommendation levels: long-term perspectives. Nutr Rev 66(10 Suppl 2):S170-S177

Norman AW (2008) From vitamin D to hormone D: fundamentals of the vitamin D endocrine system essential for good health. Am J Clin Nutr 88(2):491S-499S

Riediger ND, Othman RA, Suh M, Moghadasian MH (2009) A systematic review of the roles of n-3 fatty acis in health and disease. J Am Diet Assoc 109:668-679

Sato Y, Honda Y, Iwamoto J, Kanoko T, Satoh K (2005) Effect of folate and mecobalamin on hip fractures in patients with stroke: a randomized controlled trial. JAMA 293(9):1082-1088

Selhub J, Morris MS, Jacques PF, Rosenberg IH (2009) Folatevitamin B-12 interaction in relation to cognitive impairment, anemia, and biochemical indicators of vitamin B-12 deficiency. Am J Clin Nutr 89(2):702S-706S

Sofi F, Cesari F, Abbate R, Gensini GF, Casini A (2008) Adherence to Mediterranean diet and health status: metaanalysis. BMJ 337:a1344. doi:10.1136/bmj.a1344

Trichopoulou A, Orfanos P, Norat T, Bueno-de-Mesquita B, Ocké MC, Peeters PH, van der Schouw YT, Boeing H, Hoffmann K, Boffetta P, Nagel G, Masala G, Krogh V, Panico S, Tumino R, Vineis P, Bamia C, Naska A, Benetou V, Ferrari P, Slimani N, Pera G, Martinez-Garcia C, Navarro C, Rodriguez-Barranco M, Dorronsoro M, Spencer EA, Key TJ, Bingham S, Khaw KT, Kesse E, Clavel-Chapelon F, Boutron-Ruault MC, Berglund G, Wirfalt E, Hallmans G, Johansson I, Tjonneland A, Olsen A, Overvad K, Hundborg HH, Riboli E, Trichopoulos D (2005) Modified Mediterranean diet and survival: EPICelderly prospective cohort study. BMJ 330(7498):991

Vaes BL, Lute C, van der Woning SP, Piek E, Vermeer J, Blom HJ, Mathers JC, Müller M, de Groot LC, Steegenga WT (2010) Inhibition of methylation decreases osteoblast differentiation via a non-DNA-dependent methylation mechanism. Bone 46(2):514-523

van Meurs JB, Dhonukshe-Rutten RA, Pluijm SM, van der Klift M, de Jonge R, Lindemans J, de Groot LC, Hofman A, Witteman JC, van Leeuwen JP, Breteler MM, Lips P, Pols HA, Uitterlinden AG (2004) Homocysteine levels and the risk of osteoporotic fracture. $\mathrm{N}$ Engl $\mathrm{J}$ Med 350(20):2033-2041

Weggemans RM, Schaafsma G, Kromhout D (2009) Towards an adequate intake of vitamin D. An advisory report of the Health Council of the Netherlands. Eur J Clin Nutr 63(12):1455-1457

Williamson G, Manach C (2005) Bioavailability and bioefficacy of polyphenols in humans. II Review of 93 intervention studies. Am J Clin Nutr 81(suppl):243-55S 